\title{
Mapping the Impact of Land Use and Land Cover Change on Urban Land and Vegetation in Osun State, Nigeria
}

\author{
Abiodun O.E. ${ }^{1, *}$ and Akinola D.J. ${ }^{1}$ \\ ${ }^{1}$ Department of Surveying and Geoinformatics, University of Lagos, Akoka, Nigeria \\ Corresponding Author: *abiodunoludayo@yahoo.com
}

https://doi.org/10.36263/nijest.2019.02.0146

\begin{abstract}
Urban expansion along with other changes in land use and land cover is a global phenomenon and most parts of Western Nigeria have experienced tremendous changes in recent past. Osun state, located in Western Nigeria, was originally made up of mostly traditional farming communities. These communities have witnessed rapid urbanisation in the last few decades and most of the communities previously known to be farming communities have transformed to modern well-known cities. This project examines the use of Remote Sensing in mapping of Land Use Land Cover in Osun state over a period of 30 years (1986 to 2016) using Landsat (MSS, TM, and ETM+) images. The aim of this study is to produce a land uselland cover map of Osun state at three epochs in order to detect the changes that have taken place particularly in the built up and Vegetation areas. Landsat Images of Osun state in 1986, 2006 and 2016 were processed into five land use classes namely: Water body, Vegetation, Wetland, Built-up and Bare land. Total area of land use in each class were determined along with percentage change area, Land Consumption Rate and Land Absorption Coefficients. The result of the work shows that built-up area changed from $20.52 \%$ in 1986 to $30.71 \%$ in 2006 and then $34.45 \%$ in 2016. Land Consumption rate was 0.068 in 2016 which is indication of highly compacted living environment. The minimum Land Absorption Coefficient observed was 0.027 in between 2006 and 2016, which indicates that land is acquired for built-up development at very high rate. The resultant effect of these observed changes was a reduction of the vegetation class from 35.82\% in 1986 to $31.14 \%$ in 2006 and then $23.83 \%$ in 2016. The results in this study may influence new land policy that will enhance sustainable use of land in Osun state.
\end{abstract}

Keywords: Land Use, Epoch, Changes, Vegetation, Environment.

\subsection{Introduction}

In change detection analysis, it is required to identify differences in the state of an object or phenomenon by observing it at different times (Singh, 1989). This provides the foundation for a better understanding of the development an interaction between human and natural phenomena for a better utilisation of resources. Repetitive data, especially in the GIS environment provides the advantage of a synoptic view of the environment, and a digital data format suitable for computer processing, management and storage (Lu et al., 2004; Kennedy et al., 2009). In general, change detection involves the application of multi-temporal data sets to quantitatively analyse the temporal effects of the phenomena of interest.

Air and space-borne remote sensing data has, in the last few decades, made it possible to analyse land use and land cover information consistently. In addition, GIS tools and applications has now made it possible to easily manipulate and analyse multiple land use information simultaneously. Therefore, information such as the trend, rate, nature, location and magnitude and sometimes direction of these changes are now possible (Adeniyi et al., 1999). Land is a very important natural resource for man since life and development activities depends on it. Land use is generally used to refer to the purpose 
for which land is being utilised. Land cover on the other hand describes the status of land at a particular time (Turner et al., 1995). Land use and land cover data are essential for planners, decision makers and those concerned with land resources management. Accurate and up-to-date land use information is a requirement for proficient and sustainable development. However, accurate and current Land Use and Land Cover (LULC) information is lacking generally in Nigeria (Ezeomedo, 2006) and particularly in Osun state. This paper therefore seeks to evaluate land use and land cover changes within Osun state with particular attention to urban expansion and its impact on vegetation land. The information obtained will serve as a base for sustainable planning and development.

Osun State is located in the South-Western region of Nigeria. Most of the communities in Osun state emerged from traditionally agrarian communities. Interestingly, these communities have emerged into cities where residents are engaged in white-collar jobs. This coupled with rural-urban migration now made rapid urban expansion inevitable. It is therefore important to investigate the effect of these changes in built environment on other land uses so as to know the effect these changes could pose on the environment in near and far future.

Previous studies of Land use and Land Cover in Osun state are concentrated on some selected cities. Studies extending to the entire geographical area of Osun state are quite few and none specifically addressed the impact of urban expansion on vegetation. Among previous studies are: Analysis of Land use dynamics in Osogbo from 1986 to 2012 (Gasu et al., 2016); Assessment of the growth of Ile Ife (Ajala and Olayiwola, 2013); Assessment of Land use change in Olorunda, OdoOtin and Ifelodun Local Government areas of Osun State (Oladejo and Morenikeji, 2019); Land use and Land cover mapping of central Western Nigeria covering the cocoa growing regions between Osun and Ondo States (Oyinloye and Oloukoi, 2012) and Urban Expansion and Loss of Agricultural Land in Osogbo (Fatusin et al., 2019). Some other studies concentrated on mapping some specific land use type, for example, Orimoogunje et al., (2009) studied on wetland changes in Ilesa. In general, these studies either concentrated on some cities or a particular land use type in Osun State. None of them examined the interaction of different land use classes in Osun state. It is important to state that developmental programmes and government policies are better implemented in Nigeria at one of the three levels of government (Federal, State and Local Governments). Therefore, such studies, covering only a section of Osun State or overlapping between Osun and Ondo States would not be sufficient for decision making in the study area. This study therefore maps land use and land cover in Osun state from 1986 to 2016 .

\subsection{Methodology}

\subsection{Study area}

Osun state is Located at approximately latitude $7^{\circ} 10^{\prime}$ to $7^{\circ} 55^{\prime}$ North and longitude $4^{\circ} 30^{\prime}$ to $5^{\circ} 00^{\prime}$ East. Osun is located in the south-western part of Nigeria with capital city located at Osogbo. It is bounded in the north by Kwara State, in the east by both Ekiti and Ondo State, in the south by Ogun State and in the west by Oyo State. The sub-ethnic groups found in Osun could be classified into Ife, Ijesha, Oyo and Igbomina which formed the basis for its political divisions, although there are also people from other parts of Nigeria. Yoruba and English are the major languages spoken in Osun. People of Osun State could be classified based on their religion and beliefs into Islam, Christianity and traditional faith. The ancient town of Ile-Ife, an important and acclaimed "origin" of the Yorubas is located in Osun state. Other important cities and ancient towns include Ilesha, Oke-Ila Orangun, Ila Orangun, Ede, Iwo, Ejigbo, Ikirun, Owena and Ikire. Figure 1 shows the administrative boundaries of Osun State with its major cities and towns. 


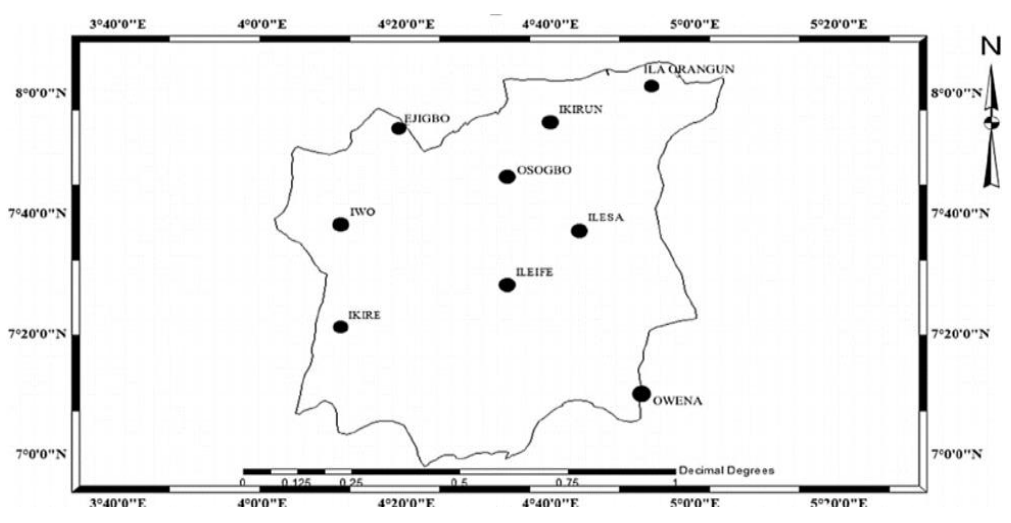

Figure 1: Map of study area

\subsection{Data acquisition}

The digitized map of Osun state was acquired from the office of the Surveyor General of Osun state. Landsat images of the study area for 1986, 2006 and 2016 were acquired from United States Geological Survey (USGS). It was difficult to secure quality images of Osun state between 1986 and 2016 except images in those epochs close to 1986 and 2016. The use of very close data epochs for a study that spans thirty years where a wide gap between the epochs is not covered may not offer an appreciable analysis of results. Therefore, although 2006 image is of low quality, it was used to at least give the idea of land use trends between 1986 and 2006. The results obtained from 1986 and 2016 will also serve as a check to inaccuracy that may be recorded from 2006 image. Table 1 below show the list of data obtained for this project and their various sources. Table 2 contain the imagery dataset details.

Table 1: Data Type

\begin{tabular}{lll}
\hline S/N & Data type & Source \\
\hline 1 & Digitized Administrative map of Osun state & \\
2 & Landsat 4 TM satellite imagery of 1984 with 30.0m resolution & USGS \\
3 & Landsat 7 ETM+ satellite imagery of 2006 with 30.0m resolution & USGS \\
4 & Landsat 8 OLI satellite imagery of 2015 with 30.0m resolution & USGS \\
\hline
\end{tabular}

Table 2: Imagery dataset details

\begin{tabular}{|c|c|c|c|c|c|}
\hline Year & Sensor & Scene ID \# & Path / Row & Date acquired & Resolution \\
\hline \multirow[t]{3}{*}{1986} & TM & LM51910551986358AAA03, & $191 / 055$ & 1986-12-18 & $30 \mathrm{~m}$ \\
\hline & & LM51900551986351AAA03, & $190 / 055$ & & \\
\hline & & LM51900541986351AAA03 & $190 / 054$ & & \\
\hline \multirow[t]{3}{*}{2006} & ETM+ & LE71900542006334ASN00, & $190 / 054$ & $2006-12-28$ & $30 \mathrm{~m}$ \\
\hline & & LE71900552006334ASN00, & $190 / 055$ & & \\
\hline & & LE71910552006341ASN00 & $191 / 055$ & & \\
\hline \multirow[t]{3}{*}{2016} & OLI & LC81900542016322LGN00, & $190 / 054$ & 2016-12-18 & $30 \mathrm{~m}$ \\
\hline & TIRS & LC81900552016002LGN00, & $190 / 055$ & & \\
\hline & & LC81910552016041LGN00 & $191 / 055$ & & \\
\hline
\end{tabular}




\subsection{Preprocessing}

Image pre-processing is also called image restoration and generally involves the correction of distortion, degradation and noise introduced during the imaging process. This process produces a corrected image that is as close as possible, both geometrically and radiometrically, to the radiant energy characteristics of the original scene. Radiometric and geometric errors are the most common types of errors encountered in remotely sensed imagery (Image Pre-processing, 1997). Since Landsat data are currently corrected by USGS/EROS to level 1T which includes the following: geometric correction with ground control points for accurate ground location and radiometric correction for accurate measurements at the sensor and no data loss, a separate pre-processing is therefore unnecessary.

\subsection{Data processing}

The extracted individual bands that make up each of the Landsat scenes acquired were stacked together into a single multispectral image using ERDAS Imagine.Figure 2 below shows the diagrammatic scheme of image staking for the 1984 image.

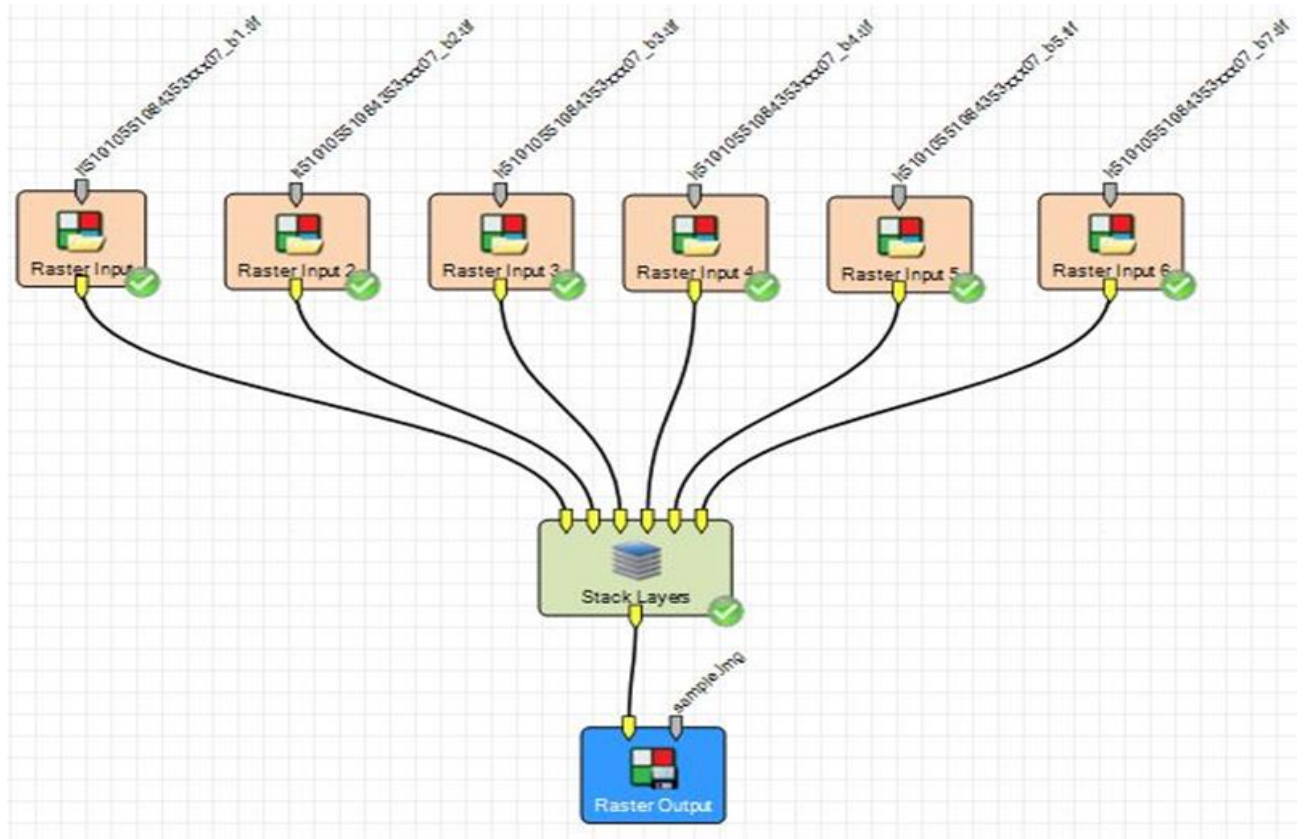

Figure 2: Diagrammatic scheme of image staking for the 1984 image.

The boundary shape file (.shp) of Osun state was converted to an area of interest file (.aoi) which was used in the clipping of the stacked multispectral Landsat imageries.The LANDSAT 7 uses the Worldwide Reference System-2 (WRS) which index orbits (paths) and scene centers (rows) into a global grid system comprising 233 paths by 248 rows (Barsi et al., 2003). Figure 3 shows the WRS imposed on the Nigerian map while the stages involved in the clipping of the study area from the stacked image is displayed in Figure 4. 


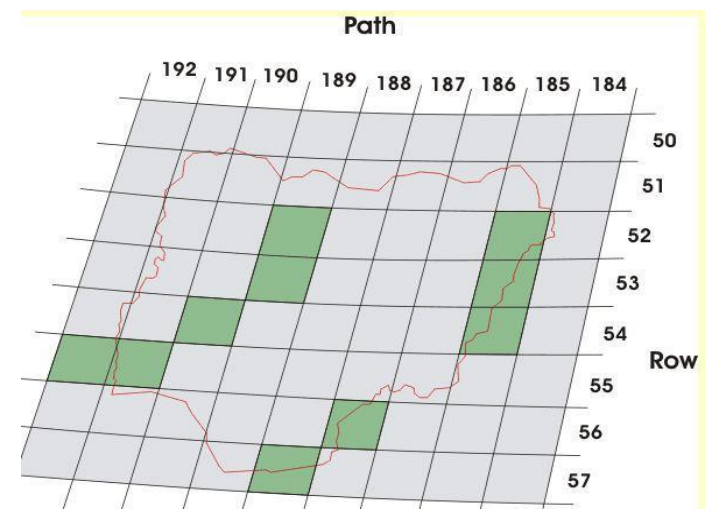

Figure 3: World Reference System (Source: www.yale.edu/ceo/DataArchive/nigeria.html)

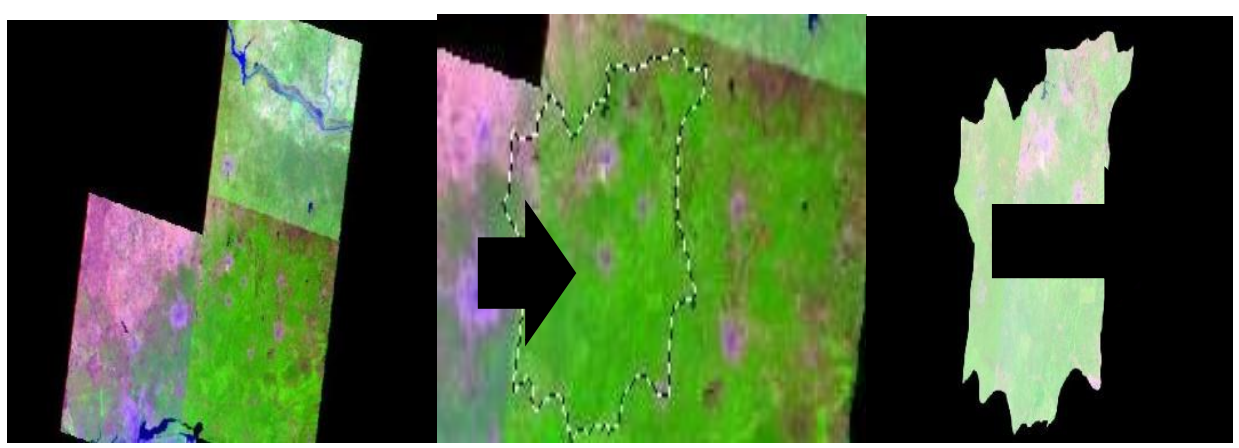

Figure 4: Clipping of the Study area from the stacked multispectra images

\subsection{Image classification}

Training of classes was done in ERDAS Imagine with the use of Area of Interest (AOI) tool combined with the Author's experience from ground truthing and visual interpretation. Maximum Likelihood a type of supervised classification technique was used in classifying the three (3) Landsat imageries. Maximum likelihood classification assumes that the statistics for each class in each band are normally distributed and calculates the probability that a given pixel belongs to a specific class. Unless the probability threshold is selected, all pixels are classified. Each pixel is assigned to the class that has the highest probability (that is, the maximum likelihood). If the highest probability is smaller than a threshold specified, the pixel remains unclassified (Richards, 1999). The images were classified into Water body, vegetation, wetland, built-up and bare land, the description of each classes are as contained in Table 3.

Table 3: The Classification Schemes used for the study

\begin{tabular}{lll}
\hline S/No & Classes & Description \\
\hline 1 & Water Body & River, permanent open water, lakes, ponds, canals and reserviors. \\
2 & Vegetation & $\begin{array}{l}\text { Trees, shrub land and semi natural vegetation, decidous, caniferous and mixed forests, } \\
\text { palms, orchads, herbs, climbers, gardens and grasslands. }\end{array}$ \\
3 & Wetland & Marshy areas susceptible to flooding \\
4 & Built-up & $\begin{array}{l}\text { All residential, commercial and industrial areas, villages settlements and transportation } \\
\text { infrastructure }\end{array}$ \\
5 & Bare land & $\begin{array}{l}\text { Fallow land, earth and sand infillings, construction and excavation sites, solid waste } \\
\text { landfills and open space. }\end{array}$ \\
\hline
\end{tabular}




\subsection{Accuracy assessment}

Accuracy assessment was carried out in order to check the correctness of the supervised classification performed on each of the Landsat Imageries. This was done in ERDAS Imagine using the Accuracy Assessment tool. The positional accuracy assessment technique was applied using 400 randomly generated reference points for each image. The multispectral images of each epoch was used as reference data. Accuracy assessment of processed images were done in two ways: the overall accuracy and the Kappa Statistics. The overall accuracy of processed images was calculated using Equation 1.

$$
P_{0}=\frac{1}{N} \sum_{i=1}^{m} n_{i i}
$$

Where $n_{i i}=$ the total number of correctly classified points by class along the diagonal of the error matrix

$P_{0}=$ Overall processing accuracy

$N=$ the total number of sampled points (Lo \& Yeung, 2007).

In the Kappa Statistics approach, the Kappa coefficient was computed using Equation 2.

$$
K P=\frac{P_{0}-P_{c}}{1-P_{c}}
$$

Where $P_{0}=$ Overall processing accuracy given in Equation 1 .

$P_{c}=$ Expected accuracy,

$K P=$ Kappa Coefficient,

$$
P_{c}=\frac{1}{N^{2}} \sum_{i=1}^{m}\left(n_{i+} \times n_{+i}\right)
$$

Where $n_{i+}=$ row sum by class

$n_{+i}=$ column sum by class

$m=$ the total number of classes (Lo \& Yeung, 2007).

\subsection{Methods of data analysis}

The methods of data analysis adopted include:

(a) Total land use area,

(b) Percentage land use area

(c) Land use dynamics degree determined by percentage change, Land Consumption rate (LCR) and Land Absorption Coefficient (LAC).

Total land use area $\left(\mathrm{Km}^{2}\right)$ for each land use type in each epoch was obtained by the total sum of individual land use types in the study area. Equation 4 below shows how each Land use type area at each epoch was calculated:

$$
\begin{aligned}
& L U \rrbracket+(a(t))=\left(\left(\sum _ { - } ( i = 1 ) ^ { \wedge } n \left(x_{-} a E i(t) y_{-}(a E i+1(t))+x_{-}(a E i+1(t)) y_{-}(a E i+2(t))+\right.\right.\right. \\
& \left.\cdots x_{-}(a E n-1(t)) y_{-} a E n\right)-\sum_{-}\left(x_{-}(a E i+1(t)) y_{-}(a E i(t))+x_{-}(a E i+2(t)) y_{-}(a E i+\right. \\
& \left.\left.\left.1(t))-\cdots x_{-} a E i(t) y_{-}(a E n-1(t))\right)\right)\right) / 2
\end{aligned}
$$


From Equation 4, $L U_{a(t)}$ is the land use type (a) at epoch $(\mathrm{t}) ; x_{a E i \ldots n(t)}$ and $y_{a E i \ldots n(t)}$ are the coordinates of each of the land use polygon in the study area.

The percentage land use area was determined by a dynamic degree model that was expressed by Equation 5.

$$
L U_{\%}=\left(\frac{L U_{a t}}{\sum_{i=1}^{n} L U_{t}}\right) \times 100 \%
$$

Where, $L U_{\%}$ is the percentage land use, $L U_{a t}$ is land use type (a) at epoch (t) and $\sum_{i=1}^{n} L U_{t}$ is the summation of all types of land use at epoch $(\mathrm{t})$.

Percentage land use change was computed using Equation 6.

$$
L U_{R}=\sum_{i=1}^{n}\left(\frac{L U_{t k}-L U_{t m}}{L U_{t m}}\right) \times 100 \%
$$

Where $L U_{R}$ is the land use rate, $L U_{t k}$ is the land use type at the end of monitoring period and $L U_{t m}$ is the land use type at the beginning of monitoring period.

Land Consumption Rate (LCR) and Land Absorption Coefficient (LAC) were determined using Equations 7 and 8. LCR and LAC analysis is applied only to the built-up land use. Built-up land use is the measure of urban development in the study area, LCR is equal to the measure of progressive spatial urbanization of a study area and LAC is equal to the measure of change of urban land by each unit increase in urban population (Olaleye et al., 2012).

$$
\begin{aligned}
& L C R=\frac{A}{P} \\
& L A C=\frac{A_{t k}-A_{t m}}{P_{t k}-P_{t m}}
\end{aligned}
$$

Where $A$ is the built-up areal extent (in hectares); $P$ is the human population; $A_{t m}$ and $A_{t k}$ are the built-up area extents for early and later years while $P_{t m}$ and $P_{t k}$ are human population figure for early and later years respectively (Dadhich et al., 2017). In estimating human population at the required epoch, Equations 9 and 10 were used.

$$
\begin{aligned}
& P_{16}=P_{06} e^{(r t)} \\
& P_{86}=\frac{P_{91}}{e^{(r t)}}
\end{aligned}
$$

Where $P_{86}, P_{91}, P_{06}$ and $P_{16}$ are human population for 1986, 1991, 2006 and 2016 respectively; $t$ is the time (years) between the base year and forecast year and $r$ is the annual population growth rate.

Osun state population data made available for 1991 and 2006 by National Bureau of Statistics (NBC, 2011) were used. In forecasting, human population for 1986, 1991 census data was used as data for base year, 2006 census data was used as base year data to forecast population for 2016. The population growth rate of $3.2 \%$ as published by NBC (2018) was used in this study. 


\subsection{Results and Discussion}

\subsection{Accuracy assessment results}

Kappa coefficient of between 0.61 and 0.80 are interpreted to be of "substantial agreement" while between 0.41 and 0.60 are interpreted as "moderate agreement" (Landis and Koch, 1977).The results of the accuracy assessment presented in Table 4 shows that 1986 and 2016 results fall within the category of substantial agreement where result of 2006 is only of moderate agreement. This again confirms the poor quality of 2006 image as earlier observed. However, with moderate agreement, 2006 results are still suitable for analysis of land use changes, although results of 1986 and 2006 would be more reliable.

Table 4: Results of accuracy assessment

\begin{tabular}{llll}
\hline Year & 1986 & 2006 & 2016 \\
\hline Accuracy (\%) & 69.67 & 63.18 & 76.67 \\
Kappa Statistic & 0.6182 & 0.5836 & 0.7083 \\
\hline
\end{tabular}

\subsection{Land use Change Results and Analysis}

The results are presented in form of maps, charts and statistical tables. They include the static, change and projected land use land cover of each class. Figures 4, 5 and 6 are the results of static land use maps for 1986, 2006 and 2016.

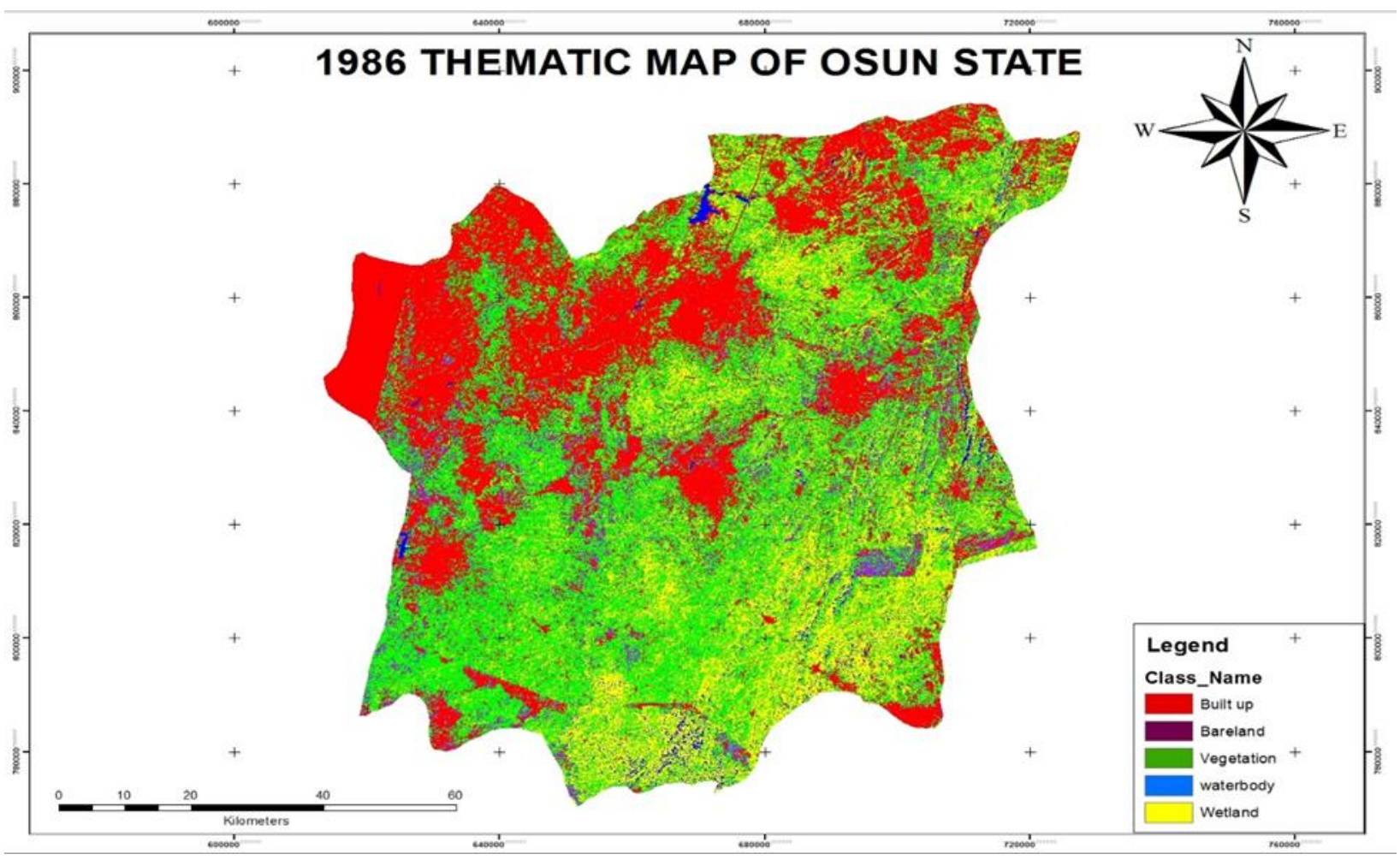

Figure 5: Thematic land use map of Osun state for 1986. 


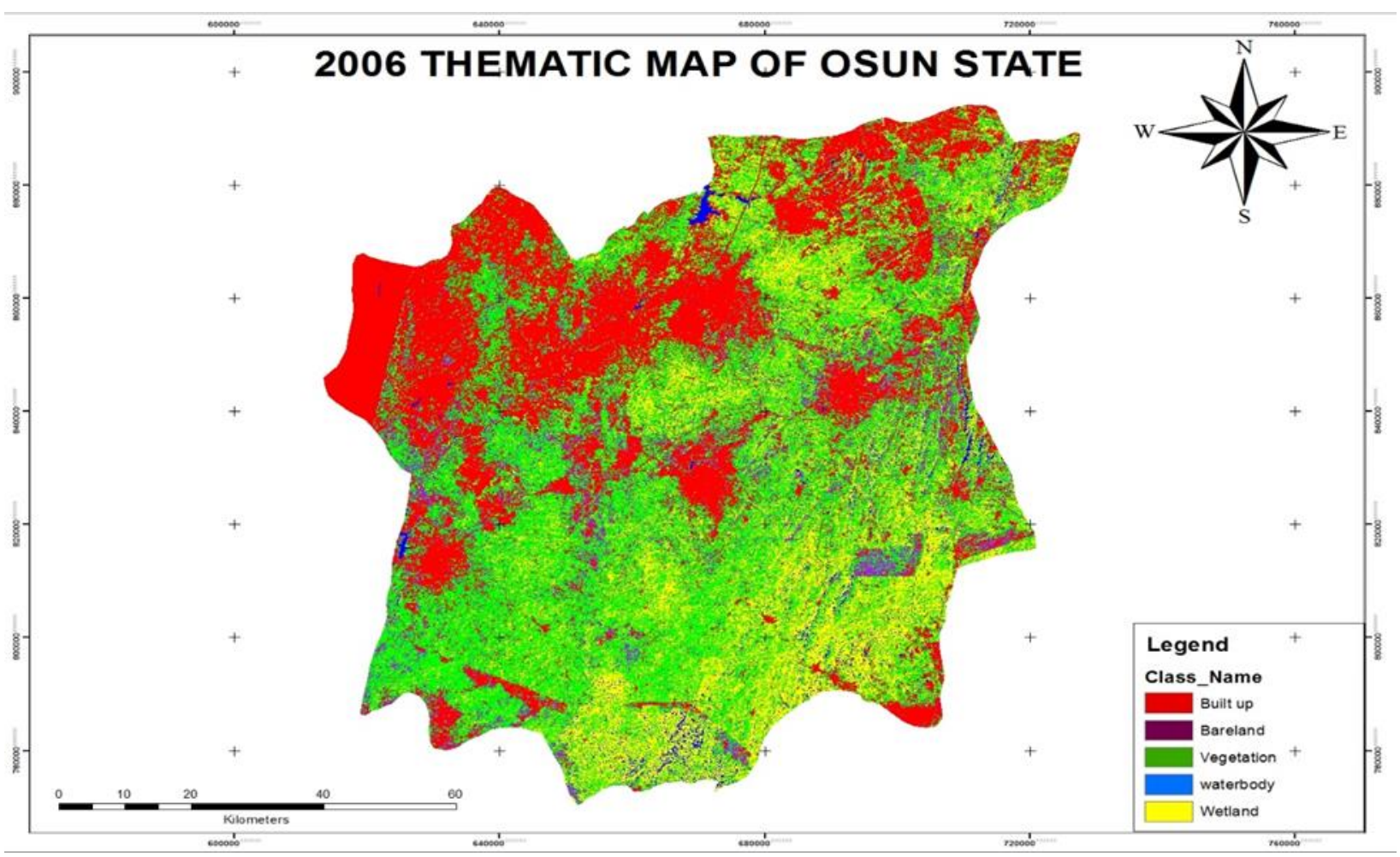

Figure 6: Thematic land use map of Osun state for 2006

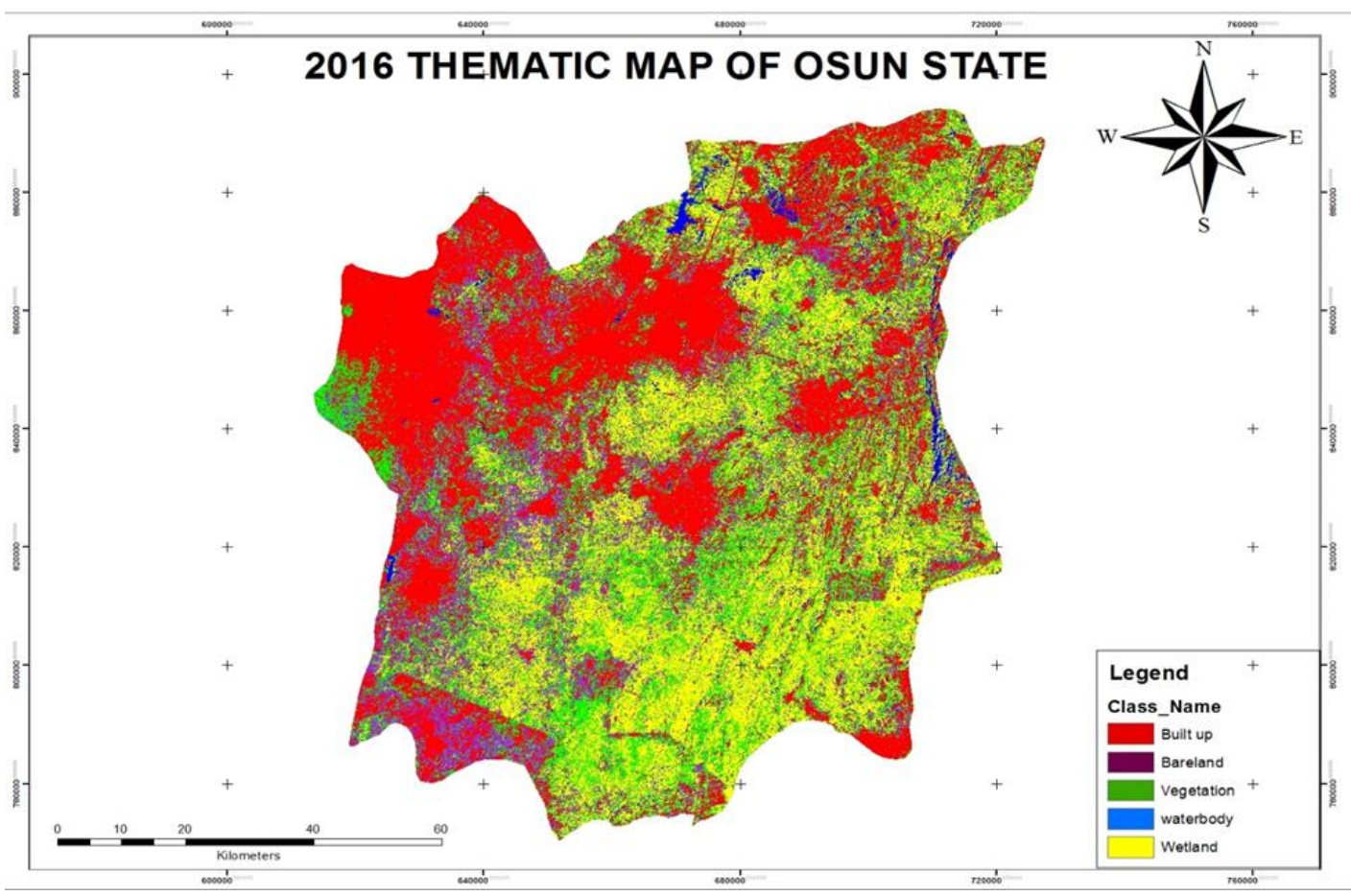

Figure 7: Thematic land use map of Osun state for 2016.

It could be observed from Figures 5, 6 and 7 that the built-up area experienced steady growth from one epoch to another while vegetation reduced. The area of land use classes in each epoch and the percentages area computed from Equation 5 is presented in Table 5. Area coverage for each land use type and the changes observed could be better appreciated using Figure 8 . 
Table 5: Land use area and percentage of land use area in each epoch

\begin{tabular}{ccccccc}
\hline \multirow{2}{*}{$\begin{array}{c}\text { Land use } \\
\text { classes }\end{array}$} & \multicolumn{3}{c}{ Land use area $\left(\mathrm{km}^{2}\right)$} & \multicolumn{3}{c}{ Percentage land area } \\
\cline { 2 - 7 } & 1986 & 2006 & 2016 & 1986 & 2006 & 2016 \\
\hline Waterbody & 226 & 223 & 224 & 2.44 & 2.41 & 2.42 \\
Vegetation & 3317 & 2883 & 2206 & 35.82 & 31.14 & 23.83 \\
Wetland & 1853 & 1854 & 1852 & 20.01 & 20.03 & 20.01 \\
Built up & 1900 & 2843 & 3190 & 20.52 & 30.71 & 34.45 \\
Bare land & 1963 & 1455 & 1787 & 21.20 & 15.72 & 19.30 \\
\hline
\end{tabular}

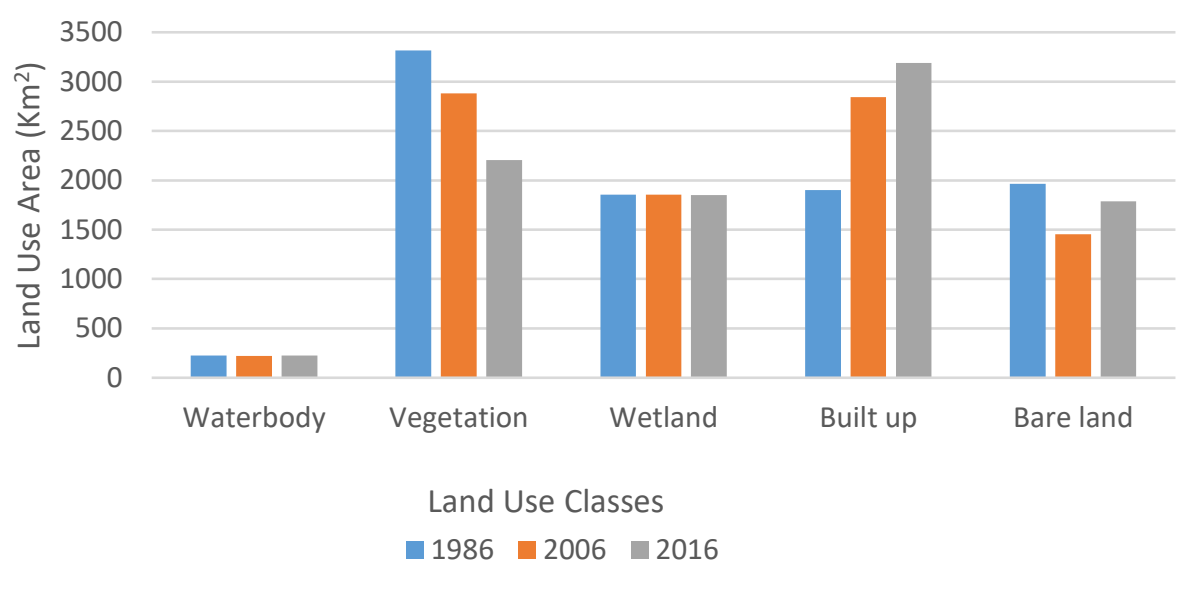

Figure 8: Land use area in each epoch

From Table 5, the poor quality of 2006 image appear to affect some of the results obtained. For example, Waterbody reduced from $226 \mathrm{Km}^{2}$ in 1986 to $223 \mathrm{Km}^{2}$ in 2006 and then increased to $224 \mathrm{Km}^{2}$ in 2016. This trend of change in water area is uncommon especially when the images used were captured in the same season. However, it is possible to ignore this since the changes under reference are marginal and error can equally be attributed to sources other than the image quality. From Figure 8 , changes in waterbody and wetland appear to be insignificant as compared to changes observed in other land use types such as built-up. This could be attributed to the fact that the images were acquired in the same season, although marginal reduction in waterbody and wetland are recorded. Changes in all the land use types and the percentage change as computed by using Equation 6 are as tabulated in Table 6. From Table 6, it can be observed that the majour changes observed from one epoch to the other are principally in built-up and vegetation classes. These changes are clearly seen in Figure 9.

Table 6: Area and percentage changes in land use $\left(\mathrm{km}^{2}\right)$

\begin{tabular}{lcccccc}
\hline \multirow{2}{*}{ Classes } & \multicolumn{3}{c}{ Area change in land use $\left(\mathrm{km}^{2}\right)$} & \multicolumn{3}{c}{ Percentage of land use change } \\
\cline { 2 - 7 } & $1986-2006$ & $2006-2016$ & $1986-2016$ & $1986-2006$ & $2006-2016$ & $1986-2016$ \\
\hline Waterbody & -3 & 1 & -2 & -1.33 & 0.45 & -0.88 \\
Vegetation & -434 & -677 & -1111 & -13.08 & -23.48 & -33.49 \\
Wetland & 1 & -2 & -1 & 0.05 & -0.11 & -0.05 \\
Built up & 943 & 347 & 1290 & 49.63 & 12.21 & 67.89 \\
Bare land & -508 & 332 & -176 & -25.88 & 22.82 & -8.97 \\
\hline
\end{tabular}




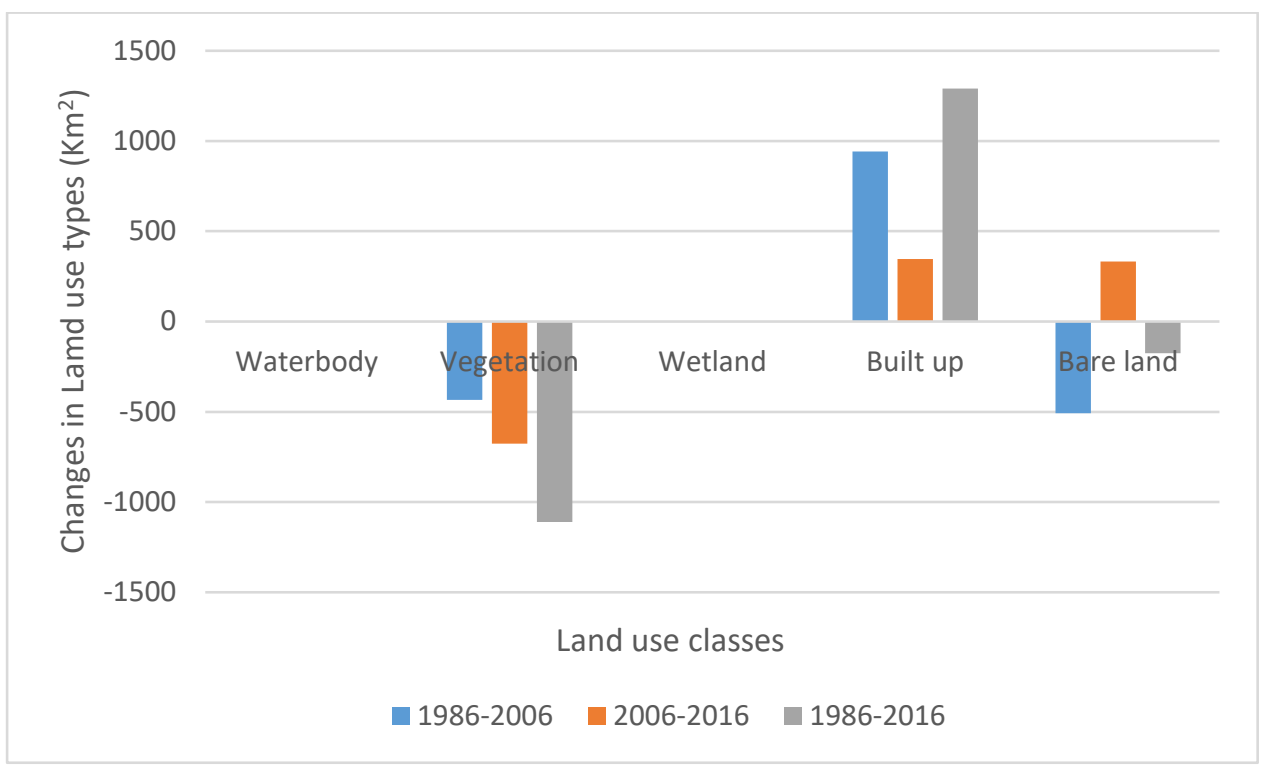

Figure 9: Changes in Land use types from one epoch to another

Results for Land Consumption rate and Land Absorption coefficient are presented in Table 7.

Table 7: Land consumption rate and land absorption coefficient

\begin{tabular}{cccccc}
\hline S/N & Year & Population & Land consumption rate & Year & Land absorption coefficient \\
\hline 1 & 1986 & $1,904,555$ & 0.099760837 & $1986 / 2006$ & 0.062351 \\
2 & 2006 & $3,416,959$ & 0.083202637 & $2006 / 2016$ & 0.026928 \\
3 & 2016 & $4,705,589$ & 0.067791726 & & \\
\hline
\end{tabular}

Land consumption rate (LCR) is a measure of compactness of urban developments in an area or city. The results of LCR was 0.099 in 1986, 0.083 in 2006 and 0.068 in 2016. LCR decreases from 1986 to 2016, this means that the cities in Osun state are becoming less compacted from 1986 to 2016. This decrease can be attributed to the fact that new areas are being developed with far less level of compactness and thus, reduces the general results of LCR in later years. It is important to note that most cities in Osun state are ancient and traditional where people with common progenitor lives together in what are referred to as "compounds". It is a recent development to have someone live in a secluded environment, away from members of his/her extended family, which could be referred to as an adaptation from the colonial masters. These results therefore suggest that more people are building homes and living away from members of their extended family. However, the LCR values are still very high using LCR classes suggested by Dadhich et al., (2017) where LCR value of above 0.012 are classed to "very high" category. This result could justify the report by Encyclopaedia Britannica (2015) that Osun has highest number of cities (10 cities) in Nigeria, followed only by Lagos and Niger with 7 cities each. It is a typical occurrence in Osun State to find two to three towns as one large city such as Ikirun/Iragbiji/Aagba/Ororuwo and Ikire/Apomu/Ikoyi. Althogh these towns may see themselves as separate entities, its effect on the global environment is that of one large city. Secondly, these cities are close to one another. For instance, Ikirun, Osogbo and Ede are cities where one can live in one of the cities and work in the other because travelling from any of these cities to the other takes not more than half an hour. The Land Absorption Coefficient (LAC) computed for 1986/2006 and 2006/2016 are 0.062 and 0.027 respectively. This result suggests that the rate at which new land is acquired for development is very high. The high rate of LAC could partly explain the 
decrease value of LCR. High LAC values suggest that the rate at which new lands are acquired for development is high. According to Table 6, wetland and water classes experienced relatively little changes within the years considered. The land use class "Bare land" could represent areas undergoing building developments, which suggests that the significant portion of the "Bare land" could actually be classed as "Built up". This may explain the changes noticed in the "Bare land" class between 1986 and 2016. Hence, the two classes where the effect of one could easily be observed on the other are Built up and Vegetation. Therefore a high value of LAC suggests that Vegetation is being converted to developed land at a very high rate. The expansion of cities and the changes in residents' traditional occupation must have greatly impacted land use. Osun state is one major agricultural states in Nigeria and these observed changes will alter agricultural productivity and in the long-term, could result in food insecurity for the rapidly growing population, particularly in Osun state and generally in Nigeria.

\subsection{Conclusions}

i. Built-up and Vegetation land use types experienced tremendous changes in the thirty-year period considered in this study. Other land use types experienced far less changes within the same period (Table 6).

ii. The rate of change in built-up class is positively high (67.89\%) within the 30 year period under consideration (Table 6). Should this rate remain for another thirty years, this could mean that the larger percentage of vegetated land would have been converted to built-up.

iii. It could be suggested that bare land is significantly a transition stage between built-up and vegetation since what constitutes bare land at a previous epoch could be significantly obtained from what constitutes built-up class in the following epoch (Table 5).

iv. There is generally a high level of crowdedness in Osun state based on the LCR value obtained in each epoch (Table 7). This could be attributed to the presence of many more cities in the state.

v. The high rate of increase in built-up class along with highly compacted cities could lead to drastic reduction in arable land for agricultural purposes which in turn could result to threat to food security and negative environmental implications.

Based on the results obtained from this study, the following are hereby recommended:

i. A new policy on urban renewal is urgently required across Osun state which will transform the old residential areas into modern settlements with desirable facilities. This will reduce the rate of city expansion that could consume substantial part of the vegetation cover;

ii. There is the need for a renewed reforestation effort to cushion the effects of high rate of city expansion.

\section{References}

Adeniyi, P.O and Omojola, A. (1999). Landuse/landcover change evaluation in SokotoRima basin of north-western Nigeria on archival remote sensing and GIS techniques, Journal of African Association of Remote Sensing of the Environment (AARSE), 1, pp. 142-146

Ajala, O. A and Olayiwola, A. M. (2013). An assessment of the growth of Ile-Ife, Osun state Nigeria, using multi-temporal imageries, Journal of Geography and Geology, 5(2), pp. 43-54. 
Arshad, A. and Shahab, F. (2012). Quantification of Land Transformation Using Remote Sensing and GIS Techniques, American Journal of Geographic Information System, 1(2), pp. 17-28.

Barsi J. A., Schott J. R., Palluconi F. D., Helder D. L., Hook S. J., Markham B. L., Chander G. and O'Donnell E. M. (2003). +"Landsat TM and ETM thermal band calibration, Canadian Journal of Remote Sensing, 29(2), pp. 141-153.

Dadhich, A. P., Goyal, R. and Pran N. D. (2017). An Assessment of Urban Space Expansion and Its Impact on Air Quality Using Geospatial Approach, Journal of Urban and Environmental Engineering, 11(1), pp. 79-87.

Ezeomedo, I.C. (2006). Change analysis of land use/land cover of Yola Metropolis to aid planning for a sustainable development. B.Tech. Project Submitted to the Department of Surveying and Geoinformatics, Federal (Moddibo-Adama) University of Technology Yola, Nigeria.

Fatusin, A.F., Oladehinde, G.J. and Ojo, V. (2019). Urban Expansion and Loss of Agricultural Land in Osogbo, Osun State Nigeria, using Multi-Temporal Imageries. Journal of African Real Estate Research, 4(1), pp.139-156

Gasu, M. B. Ebehikhalu, N, Bidmus, M. A. and Dawam, P. D. (2016), Geospatial analysis of land use dynamics in Osogbo between 1986 and 2012, Abuja Journal of Geography and Development, 4(1), pp. 52-68.

Landis, J. R. and Koch, G. G (1977). The measurement of observer agreement for categorical data. Biometrics, 33, pp. 159-174.

Lo, C. P. and Yeung, A. K. W. (Eds.) (2007). Concepts and Techniques of Geographic Information Systems (2nd ed.), Pearson Prentice Hall, Upper Saddle River, NJ.

Lu, D., Mausel, P., Brondizio, E., and Moran, E. (2004). Change detection techniques. International journal of remote sensing, 25(12), pp. 2365-2401.

National Bureau of Statistics (NBC, 2018). Demographic Statistics Bulletin 2017. Available at https://nigerianstat.gov.ng

Ndukwe, N. K. (1997). Principles of environmental remote sensing and photo Interpretation, New Concept Publishers, Lagos

Oladejo, S. O and Morenikeji, O. A, (2019). Assessment of Land Use Change using Remote Sensing and GIS Techniques in South Western Nigeria, Environmental Technology and Science Journal, 9(2), pp. 114-122.

Olaleye, J.B., Abiodun, O. E. and Asonibare, R. O. (2012). Land-use and land-cover analysis of Ilorin Emirate between 1986 and 2006 using landsat imageries, African Journal of Environmental Science and Technology, 6(4), pp. $189-198$.

Omollo, W. O., Hayombe, P. O. and Owino, F. O. (2018). Spatio-Temporal Implications of Land Use Change in Kisii Town, Kenya, American Journal of Geographic Information System, 7(2), pp. 49-57

Orimoogunje, O. O. I., Oyinloye, R. O. and Soumah. M. (2009). Geospatial Mapping of Wetlands Potential in Ilesa, Southwestern Nigeria, FIG Working Week on Surveyors Key Role in Accelerated Development, Eilat, Israel.

Oyinloye, R.O. and Oloukoi, J. (2012). Spatio-Temporal Assessment and Mapping of the Landuse Landcover Dynamics in The Central Forest Belt of Southwestern Nigeria, Research Journal of Environmental and Earth Sciences, 4(7), pp. 720-730.

Richards, J.A. and Jia, X. (2006). Remote sensing digital image analysis, an analysis (Fourth Edition), Springer-Verlag, Berlin Heidelberg. 
Singh, A. (1989), Digital Change Detection Techniques Using Remotely Sensed Data. International Journal of Remote Sensing. Vol. 10, No. 6, p. 989-1003.

Turner, B.L. II, Skole, D., Sanderson, S., Fischer, G., Fresco, L. and Leemans, R. (1995). Land-Use and Land-Cover Change; Science/Research Plan, IGBP Report No.35, HDP Report No.7. IGBP and HDP, Stockholm and Geneva, pp. 188.

Zubair, A.O., (2006). Change detection in land use and Land cover using remote sensing data and GIS: a case study of Ilorin and its environs in Kwara State, Msc Thesis, University of Ibadan, Nigeria.

\section{Cite this article as:}

Abiodun, O.E. and Akinola, D.J., 2019. Mapping the Impact of Land Use and Land Cover Change on Urban Land and Vegetation in Osun State, Nigeria. Nigerian Journal of Environmental Sciences and Technology, 3(2), pp. 317-330. https://doi.org/10.36263/nijest.2019.02.0146 